\title{
Association of Bacterial Vaginosis with Vitamin $D$ in Pregnancy: Secondary Analysis from the Kellogg Pregnancy Study
}

\author{
Anna Maya Powell, MD, MSCR ${ }^{1}$ Judy R. Shary, MS² Christopher Louden, MS 3 \\ Vishwanathan Ramakrishnan, $\mathrm{PhD}^{4}$ Allison Ross Eckard, MD ${ }^{5}$ Carol L. Wagner, MD ${ }^{2}$

\footnotetext{
${ }^{1}$ Department of Gynecology and Obstetrics, Johns Hopkins Bayview Medical Center, Baltimore, Maryland

${ }^{2}$ Division of Neonatology, Department of Pediatrics, Medical University of South Carolina, Charleston, South Carolina

${ }^{3}$ Louden Consulting, Bandera, Texas

${ }^{4}$ Department of Biostatistics, Medical University of South Carolina, Charleston, South Carolina

${ }^{5}$ Division of Infectious Diseases, Department of Medicine, Medical
} \\ University of South Carolina, Charleston, South Carolina

\begin{abstract}
Address for correspondence Carol L. Wagner, MD, Division of Neonatology, Department of Pediatrics, Medical University of South Carolina, 165 Ashley Avenue, MSC 917, Charleston, SC 29425 (e-mail: wagnercl@musc.edu).
\end{abstract} \\ Am J Perinatol Rep 2019;9:e226-e234.
}

\begin{abstract}
Keywords

- bacterial vaginosis

- vitamin D supplementation

- pregnancy

- Gram stain

Objective Bacterial vaginosis (BV) is associated with vitamin D deficiency and poor pregnancy outcomes. We studied a nested cohort from a randomized controlled trial to investigate the association between BV and vitamin D concentration in pregnancy. Study Design Subjects with randomly assigned 400 versus 4,400 IU of daily cholecalciferol (vitamin $\mathrm{D}_{3}$ ) had vaginal swabs collected for Gram staining and Nugent score calculation, as well as plasma 25-hydroxyvitamin $\mathrm{D}(25(\mathrm{OH}) \mathrm{D})$ measurement at three pregnancy time points.

Results Fifty-two (21.2\%) of the 245 women included in the analysis were diagnosed with $\mathrm{BV}$ at study entry. Women with BV were also more likely to be African American $(p<0.0001)$ and have lower 25(OH)D concentrations at 22 to 24 weeks' gestation $(p=0.03)$. There were no differences in pregnancy outcomes of interest within this group compared with the remaining study subjects. In mixed regression modeling, while race $(p=0.001)$ and age $(p=0.03)$ were significant predictors of BV prevalence independently, $25(\mathrm{OH}) \mathrm{D}$ concentration $(p=0.81)$, gestational age $(p=0.06)$, and body mass index $(p=0.87)$ were not.

Conclusion Neither vitamin D deficiency in early pregnancy nor supplementation decreased BV incidence during pregnancy. Pregnancy outcomes (preterm birth and hypertensive disorders of pregnancy) were similar among women with and without BV.
\end{abstract}

Vitamin D, a steroid prohormone best known for its role in bone health and metabolism, also plays an important role in reproductive immune regulatory functions in both the nonpregnant and pregnant states. ${ }^{1,2}$ Vitamin D deficiency, defined as a $25(\mathrm{OH}) \mathrm{D}$ concentration $<12 \mathrm{ng} / \mathrm{mL}$ by the Institute of Medicine, on the basis of increased rickets or osteomalacia risk in children and adults, ${ }^{3}$ is estimated to affect $83 \%$ of pregnant women in the first trimester and $47 \%$ of pregnant women in the third trimester. ${ }^{4,5}$ Vitamin $\mathrm{D}$ enhances innate immune function via toll-like receptor activation, inducing increased secretion of endogenous microbicides such as cathelicidin ${ }^{1}$ in response to microbial received

January 22, 2019 accepted after revision April 26, 2019
DOI https://doi.org/

10.1055/s-0039-1693163. ISSN 2157-6998.
Copyright $\odot 2019$ by Thieme Medical Publishers, Inc., 333 Seventh Avenue, New York, NY 10001, USA. Tel: +1(212) 584-4662.
License terms

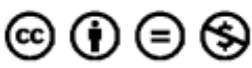


pathogens within the female genital tract. Vitamin D deficiency also puts pregnant women at higher risk for preterm birth, ${ }^{6,7}$ preeclampsia, ${ }^{8}$ gestational diabetes, as well as delivery of a small-for-gestational age neonate. ${ }^{8,9}$ While optimal supplementation dosing has not been firmly established, prior trials suggest optimal conversion to the active form of vitamin D occurs at serum concentrations $\geq 40 \mathrm{ng} / \mathrm{mL}$ in pregnancy. ${ }^{10,11}$ Wagner et $\mathrm{al}^{7}$ suggested that in pregnancy, optimal conversion of $25(\mathrm{OH}) \mathrm{D}$ to $1,25(\mathrm{OH})_{2} \mathrm{D}$, as well as reduced preterm birth rates among women, was most sig-

Table 1 Demographics for study participants with and without BV at baseline

\begin{tabular}{|c|c|c|c|c|}
\hline & $\begin{array}{l}\text { All subjects with BV } \\
\text { screening }(n=245)\end{array}$ & $\begin{array}{l}\text { BV present at } \\
\text { baseline }(n=52)\end{array}$ & $\begin{array}{l}\text { No BV at baseline } \\
(n=167)\end{array}$ & $p$-Value \\
\hline Age $(y)^{a}$ & $29( \pm 4.76)$ & $25( \pm 5.2)$ & $29( \pm 4.5)$ & 0.055 \\
\hline $\mathrm{BMI}^{\mathrm{a}}$ & $25.9( \pm 5.76)$ & $26.7( \pm 6.5)$ & $25.9( \pm 5.7)$ & 0.76 \\
\hline Gravidity $^{\mathrm{b}}$ & $2(1-3)$ & $2(1.5-4)$ & $2(1-3)$ & 0.57 \\
\hline Parity $^{\mathrm{b}}$ & $1(0-2)$ & $1(0-2)$ & $1(0-2)$ & 0.42 \\
\hline \multicolumn{5}{|l|}{ Race/ethnicity } \\
\hline Caucasian & $100(40.8 \%)$ & $8(15.4 \%)$ & $82(49.1 \%)$ & \multirow[t]{3}{*}{$<0.001$} \\
\hline African American & $68(27.8 \%)$ & $29(55.8 \%)$ & 37 (22.2\%) & \\
\hline Hispanic & 77 (31.4\%) & $15(28.9 \%)$ & $48(28.7 \%)$ & \\
\hline \multicolumn{5}{|l|}{ Insurance type } \\
\hline Self-pay/none & $62(25.3 \%)$ & $8 / 52(15.4 \%)$ & $41 / 167$ (24.6\%) & \multirow[t]{3}{*}{$<0.001$} \\
\hline Public insurance & $67(27.3 \%)$ & $29 / 52(55.8 \%)$ & $37 / 167$ (22.2\%) & \\
\hline Private insurance & $116(47.3 \%)$ & $15 / 52(28.9 \%)$ & $89 / 167$ (53.3\%) & \\
\hline \multicolumn{5}{|l|}{ Highest education level } \\
\hline More than high school & $\begin{array}{l}\text { Finished high school-116 } \\
(47.3 \%) \\
\text { Finished college-59 (24.1\%) }\end{array}$ & $24 / 49$ (49\%) & $120 / 171(70.2 \%)$ & \multirow[t]{2}{*}{0.003} \\
\hline Less than high school & $31(12.6 \%)$ & $25 / 49$ (51\%) & $51 / 171(29.8 \%)$ & \\
\hline \multicolumn{5}{|c|}{ Sexually transmitted infection in pregnancy } \\
\hline Gonorrhea & $2(0.9 \%)$ & $1 / 52(1.9 \%)$ & $1 / 167(0.6 \%)$ & 0.42 \\
\hline Chlamydia & $11(5 \%)$ & $5 / 52(9.6 \%)$ & $6 / 167(3.5 \%)$ & 0.14 \\
\hline Trichomonas & $9(4.1 \%)$ & $2 / 52(3.85 \%)$ & 7/167 (4.19\%) & 1.0 \\
\hline Syphilis & 0 & 0 & 0 & \\
\hline Herpes simplex virus & $10(4.6 \%)$ & 0 & $10 / 166(6.02 \%)$ & 0.12 \\
\hline HIV (prevalent) & 0 & 0 & 0 & \\
\hline \multicolumn{5}{|c|}{ Mean $25(\mathrm{OH}) \mathrm{D}$ concentration in pregnancy $(\mathrm{ng} / \mathrm{mL})^{\mathrm{a}}$} \\
\hline 8-15 wk (visit 1) & $26.2( \pm 9.5)$ & $23.7( \pm 8.3)$ & $26.3( \pm 9.8)$ & 0.05 \\
\hline 21-28 wk (visit 4) & $38.7( \pm 14.7)$ & $34.9( \pm 15.6)$ & $39.8( \pm 14.2)$ & 0.03 \\
\hline 31-41 wk (visit 7) & $42.4( \pm 18.6)$ & $36.7( \pm 19.8)$ & $44.8( \pm 17.3)$ & 0.056 \\
\hline \multicolumn{5}{|l|}{ Pregnancy outcome of interest } \\
\hline Gestational hypertension & $8 / 245(3.3 \%)$ & $3 / 52(5.8 \%)$ & $5 / 167(2.99 \%)$ & 0.40 \\
\hline Preeclampsia & $10 / 245(4.1 \%)$ & $3 / 52(5.8 \%)$ & $5 / 167(3.0 \%)$ & 0.40 \\
\hline Chorioamnionitis & $7 / 245(2.9 \%)$ & $2 / 52(3.9 \%)$ & $5 / 167(3.0 \%)$ & 0.67 \\
\hline Preterm birth (<37 wk) & $12 / 245(4.9 \%)$ & $3 / 52(5.8 \%)$ & $6 / 167(3.6 \%)$ & 0.45 \\
\hline \multicolumn{5}{|c|}{ Vitamin D treatment group allocation } \\
\hline $\begin{array}{l}\text { Treatment group } \\
\text { (vitamin D supplement } \\
=4,000 \text { IU daily) }\end{array}$ & $133 / 245(54.3 \%)$ & $26 / 52(50 \%)$ & $92 / 167(55.1 \%)$ & 0.52 \\
\hline
\end{tabular}

Abbreviations: BMI, body mass index; BV, bacterial vaginosis; HIV, human immunodeficiency virus; 25(OH)D, 25-hydroxyvitamin D.

${ }^{a}$ Continuous variables are reported as mean values with standard deviation. Univariate analysis performed by Wilcoxon's rank-sum test.

bMedian with interquartile range. Categorical variables were analyzed by chi-square test and Fisher's exact test. 
nificant when $25(\mathrm{OH}) \mathrm{D}$ concentrations $\geq 40 \mathrm{ng} / \mathrm{mL}$ were achieved. Using this cutoff, $>70 \%$ of pregnant women would be considered vitamin D deficient. ${ }^{12}$ Thus, vitamin D deficiency may represent an under-appreciated public health problem with a low-cost solution and positive impact on pregnancy outcomes.

Bacterial vaginosis (BV) affects almost $30 \%$ of reproductive age women in the United States, ${ }^{13}$ resulting from an overgrowth of anaerobic vaginal microbes and loss of lactobacilli. In pregnancy, BV is associated with an increased risk of preterm birth, ${ }^{14-16}$ postpartum endometritis, ${ }^{17}$ and acquisition of sexually transmitted infections. ${ }^{18-20}$ Most observational studies have identified a higher prevalence of BV among women who are vitamin D insufficient or deficient ${ }^{21-23}$; with one identifying a null association. ${ }^{24}$ In a vitamin D supplementation random- ized controlled trial (RCT), Turner et al did not demonstrate a reduction in BV recurrence in 118 nonpregnant women. ${ }^{25}$ To the best of our knowledge, there are no previously published RCTs of vitamin D supplementation investigating an impact on BV incidence in pregnancy. Since improved pregnancy outcomes may not be significant until a serum $25(\mathrm{OH}) \mathrm{D}$ concentration of at least $40 \mathrm{ng} / \mathrm{mL}$ is achieved, it is still unclear if vitamin D supplementation may result in a reduction of BV in pregnancy. Although there is insufficient evidence that screening and treatment of asymptomatic BV alone during pregnancy reduce the incidence of preterm birth, prevention of BV by way of correcting vitamin $\mathrm{D}$ deficiency may be more beneficial and has not been studied to date.

Our primary objective was to investigate the association between BV and vitamin D concentration in a nested cohort

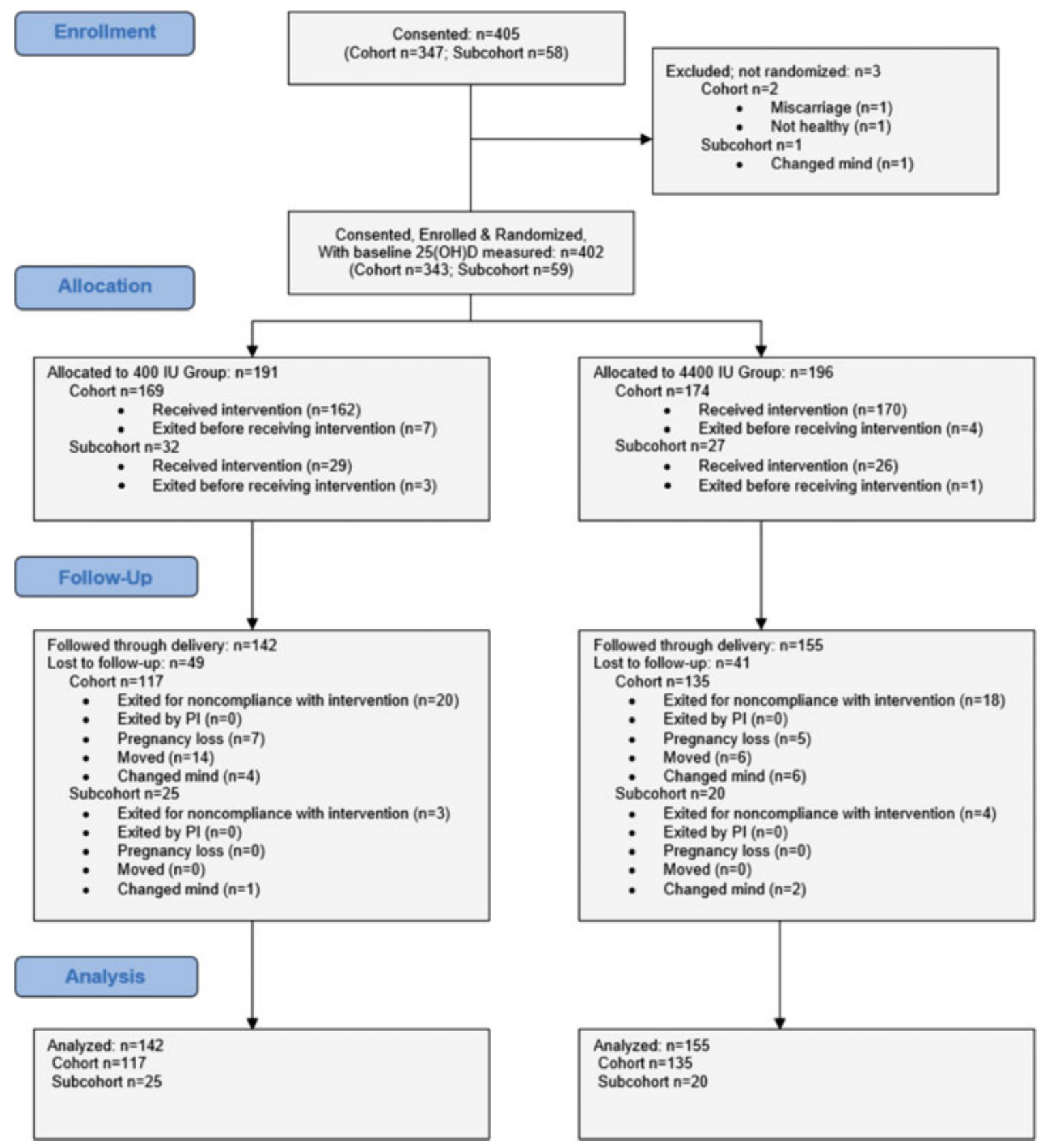

Fig. 1 CONSORT diagram for Kellogg Study and bacterial vaginosis cohort. Note: Subcohort group not used in analysis. 
from an RCT of pregnant women. Our secondary objective was to evaluate if vitamin D supplementation decreased BV incidence in pregnancy. We hypothesized that women with vitamin D deficiency would be more likely to experience BV during pregnancy and women supplemented to a 25(OH)D concentration $\geq 40 \mathrm{ng} / \mathrm{mL}$ would be less likely to experience a new BV episode in pregnancy.

\section{Methods}

This study was approved by the Institutional Review Board of the Medical University of South Carolina (Protocol \#20570) and all subjects provided written informed consent. This was a preplanned analysis within a larger RCT of 450 pregnant women, 18 to 45 years old with singleton pregnancies, enrolled between 8 and 14 weeks of gestation and followed until delivery between 2013 and 2015 (ClinicalTrials.gov, trial \#NCT01932788) (-Fig. 1). Mothers were randomized to receive the standard daily prenatal vitamin (containing $400 \mathrm{IU}$ vitamin $\left.D_{3}\right) \pm 4,000$ IU vitamin $D_{3}$ daily. Subjects were followed up monthly during pregnancy up to a total of nine study visits.

Subjects were excluded from the parent study if they had a preexisting calcium disorder, uncontrolled thyroid or parathyroid disease, requirement for chronic diuretic or cardiac medication therapy including calcium-channel blockers, sickle cell disease, sarcoidosis, or inflammatory bowel disease. A subgroup of $\sim 100$ subjects with known diabetes, hypertension, or body mass index $(\mathrm{BMI})>49 \mathrm{~kg} / \mathrm{m}^{2}$ did participate but were excluded from analysis in the present study. A sample size of 240 subjects, 120 in each arm, was calculated to be sufficient to detect a clinically important difference of 0.3 between groups in achieving a total circulating 25(OH)D concentration of at least $40 \mathrm{ng} / \mathrm{mL}$ assuming a standard deviation of 10 using a two-tailed $t$-test of difference between means with $80 \%$ power and a $5 \%$ level of significance. The total sample size was adjusted to 264 (132 per group) giving consideration to a dropout rate of $10 \%$. A stratified block randomization was used to attain equal group numbers and balanced numbers by racial/ethnic group. Adherence to treatment was assessed by monthly pill count and women with an adherence rate of $<60 \%$ predicted pill intake for 2 consecutive months exited the study ( $n=60: 7$ white/Caucasian; 18 Hispanic; and 35 black/African American [AA] women). The parent study was not powered to detect a difference in BV as a clinical outcome.

Subjects were included in this current analysis if they had at least one vaginal sample measured for BV $(n=257)$. In the present study, subjects ( $n=13$ total) were excluded from the BV analysis if spontaneous abortion ( $<20$ weeks' gestation) $(n=10)$ or intrauterine fetal demise (all $<30$ weeks) $(n=3)$ was diagnosed during the pregnancy. From the original cohort, 133 women from the 4,400 IU group and 112 from the control group were included in the current analysis.

Target vitamin D was defined as a plasma $25(\mathrm{OH}) \mathrm{D}$ concentration of $\geq 40 \mathrm{ng} / \mathrm{mL}$ based on prior pharmacokinetics studies. ${ }^{26} 25(\mathrm{OH}) \mathrm{D}$ concentrations were measured monthly, corresponding to the timing of obtained vaginal swabs at study visits in the first, second, and third trimesters prior to delivery. Initial visit, visit 4 , and visit 7 samples were obtained between 8 and 15, 22 and 28, and 31 and 41 weeks of gestation, respectively. If the subject delivered prior to 36 weeks, their last known 25(OH)D concentration and vaginal swab information were used. For the purposes of our analysis, vitamin D insufficiency was defined as $<40 \mathrm{ng} /$ $\mathrm{mL}^{26}$ and vitamin D deficiency was $<20 \mathrm{ng} / \mathrm{mL}^{3}$ ). Race and ethnicity were self-reported.

\section{Bacterial Vaginosis Diagnosis}

Vaginal swabs were collected on all participants each trimester to correspond to the timing of the $25(\mathrm{OH}) \mathrm{D}$ measurements prior to delivery and analyzed by Gram stain and Nugent score calculation. ${ }^{27}$ According to the Nugent method, women with a Nugent score of 7 to 10 were considered to have BV. The Nugent score is a Gram stain scoring system calculated by assessment of the presence of gram-positive rods, small gram-variable rods, and curved gram-variable rods per high power field. A Nugent score can range from 0 to $10 ; 0$ to 3 is considered

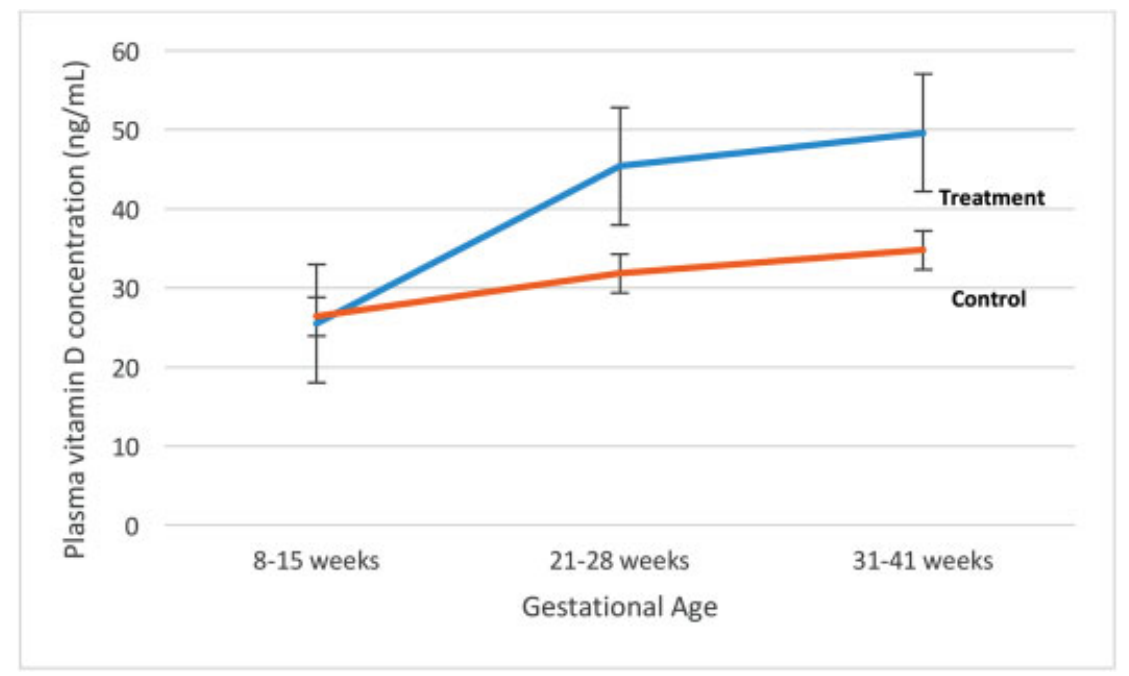

Fig. 2 Mean 25-hydroxyvitamin D concentration ( $\mathrm{ng} / \mathrm{mL}$ ) by randomization group. 
normal vaginal flora, 4 to 6 is considered intermediate flora, and 7 or greater is consistent with BV. Vaginal swabs were collected for 216, 222, and 209 subjects at visits 1, 4, and 7, respectively. Development of BV was defined as having a Nugent score $<7$ at visit 1 and $\geq 7$ at visit 4 or 7 .

\section{Measurement of 25-hydroxyvitamin D}

Whole blood samples were obtained, placed in EDTA-treated tubes and centrifuged for plasma separation. Plasma was then stored at $-80^{\circ} \mathrm{C}$ until measurement for total circulating 25 $(\mathrm{OH}) \mathrm{D}$ concentrations, measured by radioimmunoassay as per the manufacturer's protocol (DiaSorin, Stillwater, MN). The standard deviation for 25(OH)D concentration was 7 to $10 \mathrm{ng} /$ $\mathrm{mL}$. The laboratory participated in Vitamin D External Quality Assessment Scheme throughout the study period to ensure the analytical reliability of the $25(\mathrm{OH}) \mathrm{D}$ assay using National Institute of Standards and Technology standards. The interand intra-assay coefficients of variation were $<10 \%$.

\section{Timing of Vitamin D Supplementation}

Subjects from the parent study were randomized to 4,000 IU cholecalciferol versus placebo following enrollment. Thus, baseline measurements at visit 1 were obtained before randomization.

\section{Statistical Analysis}

Statistical analyses were performed using SAS 9.4 software (Cary, NC). Binomial data were compared using chi-square and Fischer's exact tests depending on the sample size. The Shapiro-Wilk's analysis was used to evaluate continuous variables for normal distribution. Normally distributed continuous variables were described as means with standard deviation and nonnormally distributed continuous variables were described as medians with a corresponding interquartile range. Continuous variables were analyzed using Student's $t$-test and Wilcoxon's rank-sum test; categorical variables were analyzed by chi-square and Fisher's exact tests. Mixed logistic regression was created using a forward iterative process to account for repeated measures over time using SAS 9.4 PROC GLIMMIX procedure (Cary, NC) with the primary outcome variable chosen as BV development. BV prevalence over time was modeled by linear mixed effects. Vitamin D concentration (continuous), gestational age, age (continuous), race/ethnicity, and prepregnancy BMI (continuous) were chosen for fixed effects, while subject identification was used as the random effect. Variables included in the model were chosen by significance in univariate analysis at the $p<0.2$ threshold. Pregnancy outcomes of interest in the regression model included gestational hypertension, preeclampsia, hemolysis, elevated liver enzymes and low platelets (HELLP) syndrome, chorioamnionitis, and preterm birth.

\section{Results}

Among all study subjects, 245 women with at least one vaginal smear available for Gram staining were included in the current analysis. Included subjects having a median age of 29 years were predominantly non-Hispanic white race and had a mean

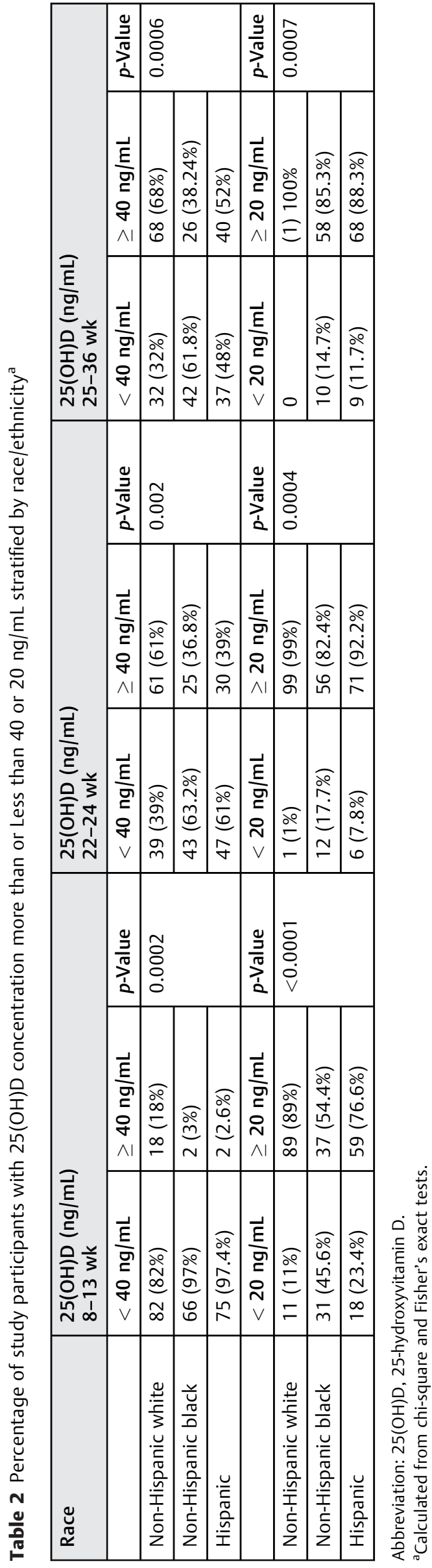


prepregnancy BMI of $25.9 \mathrm{~kg} / \mathrm{m}^{2}$. A majority were privately insured and had finished college ( - Table $\mathbf{1}$ ). Chlamydia was the most common sexually transmitted infection diagnosed in pregnancy (5\%), followed by herpes simplex virus. At initial visit (8-13 weeks), the mean 25(OH)D concentration was $26.2 \mathrm{ng} / \mathrm{mL}( \pm 9.5 \mathrm{ng} / \mathrm{mL})$, which increased to a mean concentration of $42.4 \mathrm{ng} / \mathrm{mL}( \pm 18.6 \mathrm{ng} / \mathrm{mL})$ by delivery. Almost $5 \%$ of participants experienced preterm delivery ( $<37$ weeks' gestation). The second most common complication of pregnancy was preeclampsia (4.1\%) (-Fig. 1).

\section{Mean 25(OH)D Concentration by Randomization \\ Group}

Study participants in treatment $(4,000+400$ IU in prenatal vitamin) versus control (400 IU in prenatal vitamin) arm had statistically significantly different $25(\mathrm{OH}) \mathrm{D}$ concentrations at 21 to 28 weeks ( $p<0.0001)$ and 31 to 41 weeks $(p<0.0001)$ (-Table 1). - Fig. 2 shows mean 25(OH)D concentrations throughout the study period by randomization group.

Significant differences in $25(\mathrm{OH}) \mathrm{D}$ concentrations were also apparent throughout the study period when stratified by race, randomization group, and prepregnancy BMI. Among AA women, $61.8 \%$ had $25(\mathrm{OH}) \mathrm{D}$ concentrations $<40 \mathrm{ng} / \mathrm{mL}$ at visit 7 (-Table 2). AA women were significantly more likely to have $25(\mathrm{OH}) \mathrm{D}$ concentrations $<20 \mathrm{ng} / \mathrm{mL}$ at all three time points ( $p<0.0001, p=0.0004$, and $p=0.0007$, respectively). $25(\mathrm{OH}) \mathrm{D}$ concentrations were significantly different at visits 4 $(p<0.0001)$ and $7(p<0.0001)$ by randomization group among study participants. Women with a prepregnancy BMI $\geq 30 \mathrm{~kg} / \mathrm{m}^{2}$ were significantly more likely to have a $25(\mathrm{OH}) \mathrm{D}$ concentration $<40 \mathrm{ng} / \mathrm{mL}$.

\section{Baseline BV}

Based on a Nugent score of 7 to 10, BV was diagnosed in 52 women at initial visit (21.2\%). Compared with women who did not have BV at baseline, these subjects were not significantly younger (mean age 25 vs. 29 years, $p=0.055$ ), but more likely to be AA ( 55.8 vs. $22.2 \%, p<0.001$ ), covered under public insurance (55.8 vs. $22.2 \%, p<0.001)$, and significantly less likely to have more than a high school education ( - Table $1 ; p=0.003$ ). Of note, $70.2 \%$ of AA women were covered under public insurance. Women with BV at baseline also had significantly lower mean 25(OH)D concentrations at 8 to 15 weeks (visit 1 ) and 21 to 28 weeks (visit 4) (visit $1, p=0.05$; visit $4, p=0.03$ ). There were no significant differences in pregnancy outcomes of interest among women with and without BV at baseline. - Fig. 3 demonstrates BV prevalence by randomization group throughout pregnancy.

\section{BV Development in Pregnancy}

Sixteen women developed BV during pregnancy and were significantly younger than those who did not ( 26.5 vs. 29 years; $p=0.02$ ). There were no other differences noted in terms of race/ethnicity, prepregnancy $\mathrm{BMI}$, insurance type, education level, or incidence of sexually transmitted infections (-Table 3). There were also no significant differences in mean 25(OH)D concentrations throughout pregnancy or among pregnancy outcomes of interest between women who did and did not develop BV during pregnancy. In univariate analysis, only prepregnancy BMI category was significantly associated (unadjusted odds ratio: $0.72,95 \%$ confidence interval: $1.01-4.2, p=0.046$ ) with BV development; however, this variable was no longer significant following adjustment for race, age, treatment group, and $25(\mathrm{OH}) \mathrm{D}$ concentrations at each time point by multivariate logistic regression. Per cent change in vitamin D concentrations between visits 1 and 4, 4 and 7 , and 1 and 7 were calculated and did not significantly correlate with BV prevalence.

\section{Vitamin D Concentration and BV Prevalence}

Overall, the relationship between $25(\mathrm{OH}) \mathrm{D}$ concentration and BV was not strong or statistically significant. The unadjusted baseline 25(OH)D was significantly associated with BV at visit $1(p=0.01)$ but not with BV development in pregnancy $(p=0.14)$. Following adjustment for age, race/ethnicity, gestational age, and prepregnancy BMI, this relationship between baseline 25(OH)D and BV was no longer significant. While -Fig. 3 demonstrates an apparent increase in BV

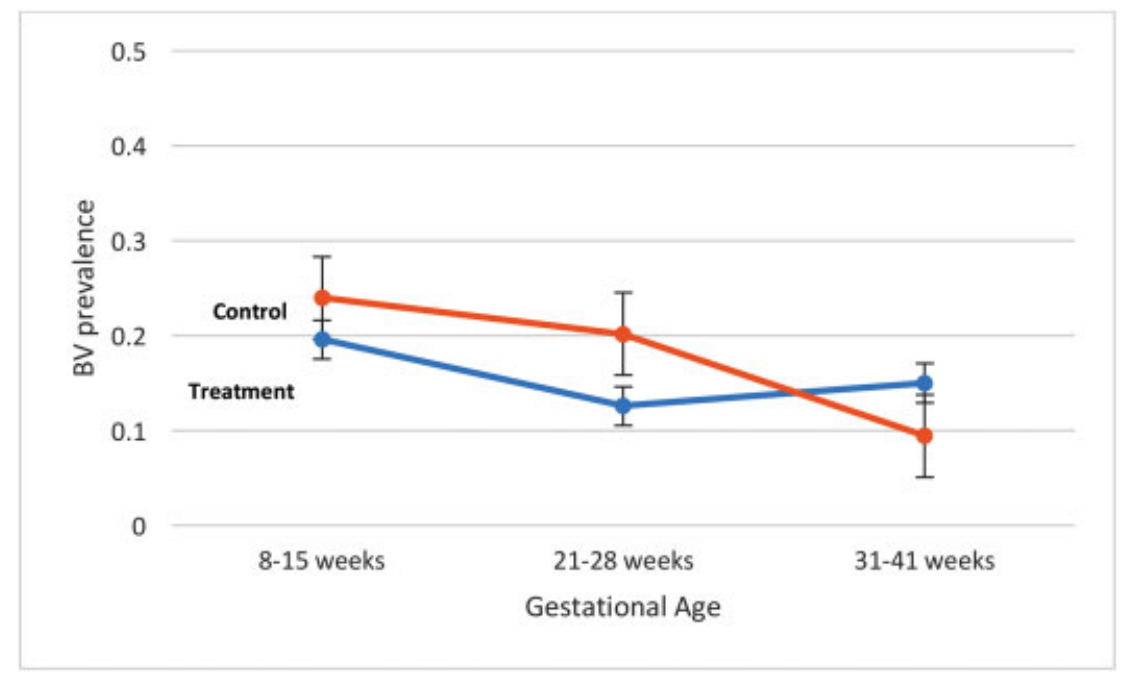

Fig. 3 Bacterial vaginosis (BV) prevalence by randomization group. 
Table 3 Demographics for study participants who did and did not develop BV during pregnancy ${ }^{\mathrm{a}}$

\begin{tabular}{|c|c|c|c|}
\hline & $\begin{array}{l}\text { BV developed } \\
\text { during pregnancy } \\
(n=16)^{\mathrm{a}}\end{array}$ & $\begin{array}{l}\text { No BV developed } \\
\text { during pregnancy } \\
(n=216)\end{array}$ & $p$-Value \\
\hline Age $(y)^{b}$ & $26.5( \pm 5.1)$ & $29( \pm 4.7)$ & 0.022 \\
\hline $\mathrm{BMI}^{\mathrm{b}}$ & $26.1( \pm 7.5)$ & $26.0( \pm 5.7)$ & 0.13 \\
\hline Gravidity $^{c}$ & $3(2-4)$ & $2(1-3)$ & 0.43 \\
\hline Parity $^{c}$ & $1(1-2)$ & $1(0-2)$ & 0.19 \\
\hline \multicolumn{4}{|l|}{ Race/ethnicity } \\
\hline Caucasian & $4(25 \%)$ & $90(41.7 \%)$ & \multirow[t]{3}{*}{0.42} \\
\hline African American & $6(37.5 \%)$ & $62(28.7 \%)$ & \\
\hline Hispanic & $6(37.5 \%)$ & $64(29.6 \%)$ & \\
\hline \multicolumn{4}{|l|}{ Insurance type } \\
\hline Self-pay/none & $4(25 \%)$ & $51(23.6 \%)$ & \multirow[t]{3}{*}{0.32} \\
\hline Public insurance & $7(43.8 \%)$ & $60(27.8 \%)$ & \\
\hline Private insurance & $5(31.3 \%)$ & $105(48.6 \%)$ & \\
\hline \multicolumn{4}{|l|}{ Highest education level } \\
\hline More than high school & $8 / 16(50 \%)$ & $142 / 216(65.7 \%)$ & \multirow[t]{2}{*}{0.21} \\
\hline Less than high school & $8 / 16(50 \%)$ & $74 / 216(34.2 \%)$ & \\
\hline \multicolumn{4}{|c|}{ Sexually transmitted infections in pregnancy } \\
\hline Gonorrhea & $1 / 16(6.3 \%)$ & $1 / 216(0.46 \%)$ & 0.14 \\
\hline Chlamydia & $2 / 16(12.5 \%)$ & $9 / 216(4.2 \%)$ & 0.17 \\
\hline Trichomonas & $1 / 16(6.3 \%)$ & $8 / 216(3.7 \%)$ & 0.48 \\
\hline Syphilis & 0 & 0 & 0 \\
\hline Herpes simplex virus & $1 / 16(6.3 \%)$ & $9 / 215(4.19 \%)$ & 0.52 \\
\hline HIV (prevalent) & 0 & 0 & 0 \\
\hline \multicolumn{4}{|c|}{ Mean $25(\mathrm{OH})$ D concentration in pregnancy $(\mathrm{ng} / \mathrm{mL})$} \\
\hline $8-15$ wk (visit 1) & $22.05( \pm 8.4)$ & $26.3( \pm 9.6)$ & 0.72 \\
\hline $21-28$ wk (visit 4) & $36.5( \pm 12.8)$ & $38.7( \pm 15.1)$ & 0.61 \\
\hline 31-41 wk (visit 7) & $47.6( \pm 15.9)$ & $42.2( \pm 19.0)$ & 0.98 \\
\hline \multicolumn{4}{|l|}{ Pregnancy outcome of interest } \\
\hline Gestational HTN & 0 & $8 / 216(3.7 \%)$ & 1.0 \\
\hline Preeclampsia & 0 & $9 / 216(4.2 \%)$ & 1.0 \\
\hline Chorioamnionitis & $1 / 16(6.3 \%)$ & $6 / 216(2.8 \%)$ & 0.4 \\
\hline Preterm birth & $1 / 16(6.3 \%)$ & $9 / 216(4.2 \%)$ & 0.52 \\
\hline \multicolumn{4}{|c|}{ Vitamin D treatment group allocation } \\
\hline $\begin{array}{l}\text { Treatment group (vitamin } \\
\text { D supplement }=4,000 \mathrm{IU} \text { ) }\end{array}$ & $10 / 16(62.5 \%)$ & $114 / 216(52.8 \%)$ & 0.45 \\
\hline
\end{tabular}

Abbreviations: BV, bacterial vaginosis; HIV, human immunodeficiency virus; HTN, hypertension; 25(OH)D, 25-hydroxyvitamin D.

aWomen with BV at baseline were excluded from this analysis.

${ }^{b}$ Continuous variables are reported as mean values with standard deviation. Univariate analysis performed by Wilcoxon's rank-sum test.

'Median with interquartile range. Categorical variables were analyzed by chi-square test and Fisher's exact test.

prevalence by 31 to 41 weeks in the treatment group $(4,400$ IU supplement) compared with controls, this trend was not statistically different $(p=0.22)$ and was similar across all racial groups. - Fig. 4 demonstrates this relationship with an unadjusted area under the curve $=0.611$ by receiver-operating characteristic curve. BV was significantly more prevalent among AA compared with Caucasian women at visits 4 $(p=0.01)$ and $7(p=0.007)$. In a linear mixed-effects model, age $(p=0.02)$ and race/ethnicity $(p=0.0002)$ were significant predictors for BV. Vitamin D concentration $(p=0.81)$, gestational age ( $p=0.06)$, and prepregnancy BMI $(p=0.87)$ were not significant predictors. The influence of race/ethnicity was found to overpower that of vitamin D concentration with different iterations of the model. When modeling BV 


\section{ROC Curve (VD predicting BV)}

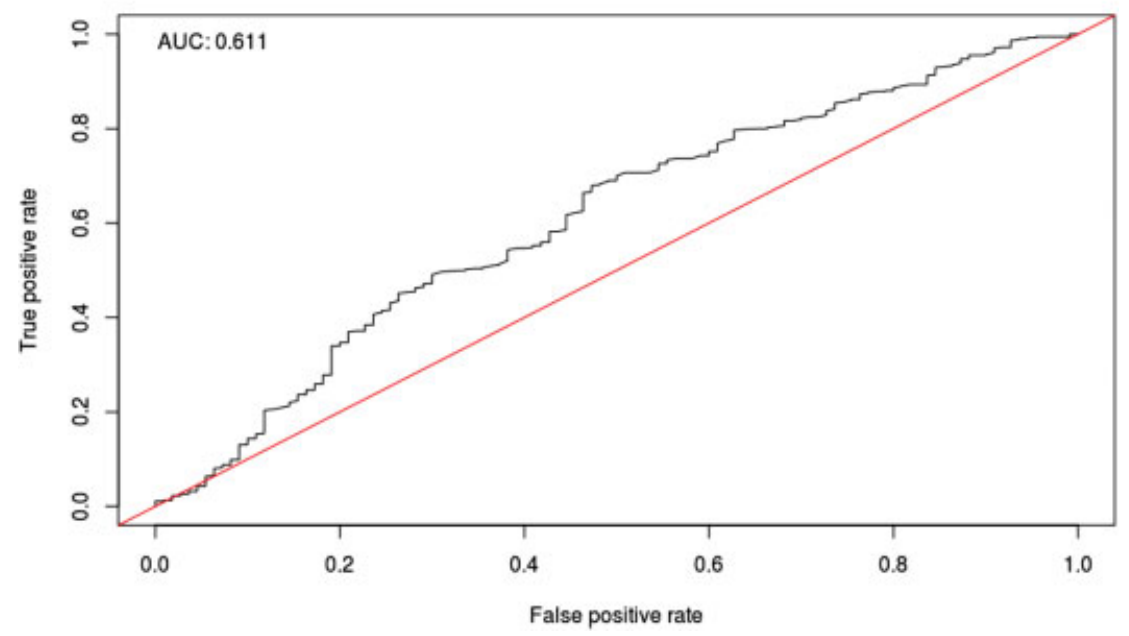

Fig. 4 Unadjusted ROC curve for 25(OH)D (VD) concentration and BV. AUC, area under the curve; BV, bacterial vaginosis; ROC, receiveroperating characteristic; VD, vitamin D; 25(OH)D, 25-hydroxyvitamin D.

prevalence over time just among AA women, it, however, still showed no significant effect of vitamin D concentration either as a continuous or categorical variable (at 40 or $20 \mathrm{ng} / \mathrm{mL}$ levels).

\section{Discussion}

In this nested cohort from the Kellogg Pregnancy Study RCT, baseline vitamin D deficiency and vitamin D supplementation did not appear to have a significant impact on incidence or prevalence of BV during pregnancy, after accounting for race/ethnicity, age, and prepregnancy BMI. Consistent with prior reports in the literature, race was an independent, significant predictor for BV. It is reasonable to compare our results with previous studies because there does not appear to be any evidence that BV is more common in pregnancy. Our results are also consistent with the previously published $\mathrm{RCT}$ investigating vitamin D supplementation to reduce BV recurrence in nonpregnant women, which showed no significant difference in BV recurrence based on randomized treatment group. Subjects in our study had higher mean plasma $25(\mathrm{OH}) \mathrm{D}$ concentrations at trial completion, compared with previous studies. ${ }^{25,28}$ While a dose-dependent effect of vitamin D appears to impact other pregnancy outcomes, it did not appear to significantly impact BV diagnosis in pregnancy.

BV is known to cause a localized inflammatory response in the vagina. ${ }^{13,29,30}$ It is also associated with altered cervicovaginal inflammatory cytokines ${ }^{13,31}$ and absent antimicrobial peptides. ${ }^{32}$ Thus, vitamin D plays a plausible role within the female genital tract by altering the innate immune response to pathogens such as BV. Vitamin D receptors are present on many cells of the female genital tract, which regulate expression of cathelicidin antimicrobial peptides $^{2,33}$ which, in turn, may protect the female genital tract. In support of this hypothesis, vitamin $\mathrm{D}$ receptor knockout mice have significantly decreased intestinal lactobacilli concentrations. In the human vagina, decreased lactobacilli concentration is associated with vaginal dysbiosis. ${ }^{33}$ While not currently known, there may still be a dose-dependent effect of vitamin $D$ on the female genital tract, which may be further affected by race and pregnancy. Additional factors not studied in our RCT may mitigate this effect.

Strengths of this study include a relatively large sample size and randomized study design, as well as consistent Nugent score reading by one investigator (A.M.P.). The sample size may not have provided enough power to detect racial differences in BV by $25(\mathrm{OH}) \mathrm{D}$ concentration, however. More subtle differences between groups may also not have been detectable by Gram stain or Nugent score assignment. Additional limitations include the possible confounding biological effects of AA race and vitamin D supplementation; however, even after isolating the race variable, no significant effect of vitamin D supplementation on BV prevalence was observed. Clearly, additional studies would be needed to further delineate the role of vitamin $\mathrm{D}$ and the impact of supplementation on the female genital tract and its microbiome, and particularly during pregnancy. A matched case-control design could further clarify racial differences and effects of vitamin D supplementation on the incidence of BV.

\section{Conclusion}

Vitamin D supplementation did not appear to have a significant impact on incidence or prevalence of BV during pregnancy, even after accounting for race, age, and treatment group assignment.

Note

This study was presented at the annual Infectious Disease Society for Obstetricians and Gynecologists in Park City, UT, August 2017.

\section{Disclosure}

The authors have no relevant financial disclosure. 


\section{Funding}

Funded by the W. K. Kellogg Foundation and by the South Carolina Clinical \& Translational Research (SCTR) Institute, with an academic home at the Medical University of South Carolina, NIH/NCAT grant number UL1 TR000062. Vitamin D study drug and placebo provided by Church \& Dwight (Princeton, NJ).

\section{Conflict of Interest}

Dr. Wagner reported grants from W. K. Kellogg Foundation and South Carolina Clinical \& Translational Research (SCTR) Institute, during the conduct of the study.

\section{References}

1 Aranow C. Vitamin D and the immune system. J Investig Med 2011;59(06):881-886

2 Tamblyn JA, Hewison M, Wagner CL, Bulmer JN, Kilby MD. Immunological role of vitamin $\mathrm{D}$ at the maternal-fetal interface. J Endocrinol 2015;224(03):R107-R121

3 National Institutes of Health OoDS. Vitamin D: Fact Sheet for Health Professionals. 2016. Available at: https://ods.od.nih.gov/ factsheets/VitaminD-HealthProfessional/. Accessed December 11, 2018

4 Ginde AA, Sullivan AF, Mansbach JM, Camargo CA Jr. Vitamin D insufficiency in pregnant and nonpregnant women of childbearing age in the United States. Am J Obstet Gynecol 2010;202(05): 436.e1-436.e8

5 Ginde AA, Liu MC, Camargo CA Jr. Demographic differences and trends of vitamin D insufficiency in the US population, 19882004. Arch Intern Med 2009;169(06):626-632

6 Amegah AK, Klevor MK, Wagner CL. Maternal vitamin D insufficiency and risk of adverse pregnancy and birth outcomes: a systematic review and meta-analysis of longitudinal studies. PLoS One 2017;12(03):e0173605

7 Wagner CL, Baggerly C, McDonnell S, et al. Post-hoc analysis of vitamin D status and reduced risk of preterm birth in two vitamin D pregnancy cohorts compared with South Carolina March of Dimes 2009-2011 rates. J Steroid Biochem Mol Biol 2016;155(Pt B):245-251

8 Wei SQ, Qi HP, Luo ZC, Fraser WD. Maternal vitamin D status and adverse pregnancy outcomes: a systematic review and meta-analysis. J Matern Fetal Neonatal Med 2013;26(09): 889-899

9 Weinert LS, Reichelt AJ, Schmitt LR, et al. Vitamin D deficiency increases the risk of adverse neonatal outcomes in gestational diabetes. PLoS One 2016;11(10):e0164999

10 Dawodu A, Saadi HF, Bekdache G, Javed Y, Altaye M, Hollis BW. Randomized controlled trial (RCT) of vitamin D supplementation in pregnancy in a population with endemic vitamin D deficiency. J Clin Endocrinol Metab 2013;98(06):2337-2346

11 McDonnell SL, Baggerly KA, Baggerly CA, et al. Maternal 25(OH)D concentrations $\geq 40 \mathrm{ng} / \mathrm{mL}$ associated with $60 \%$ lower preterm birth risk among general obstetrical patients at an urban medical center. PLoS One 2017;12(07):e0180483

12 Hollis BW, Wagner CL. Vitamin D and pregnancy: skeletal effects, nonskeletal effects, and birth outcomes. Calcif Tissue Int 2013;92 (02):128-139

13 Mitchell C, Marrazzo J. Bacterial vaginosis and the cervicovaginal immune response. Am J Reprod Immunol 2014;71(06): 555-563

14 Hay PE, Lamont RF, Taylor-Robinson D, Morgan DJ, Ison C, Pearson J. Abnormal bacterial colonisation of the genital tract and subsequent preterm delivery and late miscarriage. BMJ 1994;308 (6924):295-298
15 Qin LL, Lu FG, Yang SH, Xu HL, Luo BA. Does maternal vitamin D deficiency increase the risk of preterm birth: a meta-analysis of observational studies. Nutrients 2016;8(05):E301

16 Bodnar LM, Platt RW, Simhan HN. Early-pregnancy vitamin D deficiency and risk of preterm birth subtypes. Obstet Gynecol 2015;125(02):439-447

17 Jacobsson B, Pernevi P, Chidekel L, Jörgen Platz-Christensen J. Bacterial vaginosis in early pregnancy may predispose for preterm birth and postpartum endometritis. Acta Obstet Gynecol Scand 2002;81(11):1006-1010

18 Murphy K, Mitchell CM. The interplay of host immunity, environment and the risk of bacterial vaginosis and associated reproductive health outcomes. J Infect Dis 2016;214(Suppl 1): S29-S35

19 Cherpes TL, Meyn LA, Krohn MA, Lurie JG, Hillier SL. Association between acquisition of herpes simplex virus type 2 in women and bacterial vaginosis. Clin Infect Dis 2003;37(03):319-325

20 Wiesenfeld HC, Hillier SL, Krohn MA, Landers DV, Sweet RL. Bacterial vaginosis is a strong predictor of Neisseria gonorrhoeae and Chlamydia trachomatis infection. Clin Infect Dis 2003;36(05): 663-668

21 Bodnar LM, Krohn MA, Simhan HN. Maternal vitamin D deficiency is associated with bacterial vaginosis in the first trimester of pregnancy. J Nutr 2009;139(06):1157-1161

22 Davis LM, Chang SC, Mancini J, Nathanson MS, Witter FR, O'Brien KO. Vitamin D insufficiency is prevalent among pregnant African American adolescents. J Pediatr Adolesc Gynecol 2010;23(01):45-52

23 Dunlop AL, Taylor RN, Tangpricha V, Fortunato S, Menon R. Maternal vitamin D, folate, and polyunsaturated fatty acid status and bacterial vaginosis during pregnancy. Infect Dis Obstet Gynecol 2011;2011:216217

24 Turner AN, Carr Reese P, Chen PL, et al. Serum vitamin D status and bacterial vaginosis prevalence and incidence in Zimbabwean women. Am J Obstet Gynecol 2016;215(03):332.e1-332.e10

25 Turner AN, Carr Reese P, Fields KS, et al. A blinded, randomized controlled trial of high-dose vitamin D supplementation to reduce recurrence of bacterial vaginosis. Am J Obstet Gynecol 2014;211(05):479.e1-479.e13

26 Hollis BW, Johnson D, Hulsey TC, Ebeling M, Wagner CL. Vitamin D supplementation during pregnancy: double-blind, randomized clinical trial of safety and effectiveness. J Bone Miner Res 2011;26 (10):2341-2357

27 Nugent RP, Krohn MA, Hillier SL. Reliability of diagnosing bacterial vaginosis is improved by a standardized method of gram stain interpretation. J Clin Microbiol 1991;29(02):297-301

28 Taheri M, Baheiraei A, Foroushani AR, Nikmanesh B, Modarres M. Treatment of vitamin D deficiency is an effective method in the elimination of asymptomatic bacterial vaginosis: a placebo-controlled randomized clinical trial. Indian J Med Res 2015;141(06): 799-806

29 Cole AM, Cole AL. Antimicrobial polypeptides are key anti-HIV-1 effector molecules of cervicovaginal host defense. Am J Reprod Immunol 2008;59(01):27-34

30 Balkus J, Agnew K, Lawler R, Mitchell C, Hitti J. Effects of pregnancy and bacterial vaginosis on proinflammatory cytokine and secretory leukocyte protease inhibitor concentrations in vaginal secretions. J Pregnancy 2010;2010:385981

31 Ferreira CS, Marconi C, Parada CM, et al. Bacterial vaginosis in pregnant adolescents: proinflammatory cytokine and bacterial sialidase profile. Cross-sectional study. Sao Paulo Med J 2015;133 (06):465-470

32 Valore EV, Wiley DJ, Ganz T. Reversible deficiency of antimicrobial polypeptides in bacterial vaginosis. Infect Immun 2006;74(10): 5693-5702

33 Jin D, Wu S, Zhang YG, et al. Lack of vitamin D receptor causes dysbiosis and changes the functions of the murine intestinal microbiome. Clin Ther 2015;37(05):996-1009.e7 